\title{
CHOP (GADD153) and its oncogenic variant, TLS-CHOP, have opposing effects on the induction of $G_{1} / S$ arrest
}

\author{
M. Vittoria Barone, ${ }^{1}$ Anne Crozat, ${ }^{2}$ Arash Tabaee, ${ }^{2}$ Lennart Philipson, ${ }^{1,3}$ and David Ron ${ }^{2,4}$ \\ ${ }^{1}$ European Molecular Biology Laboratory, Heidelberg, Germany; ${ }^{2}$ Departments of Medicine and Cell Biology and the Kaplan \\ Cancer Center, New York University Medical Center, New York, New York 10016 USA
}

\begin{abstract}
The growth arrest and DNA damage-inducible gene CHOP (GADD153) encodes a small nuclear protein from the C/EBP family, originally isolated from adipocytes in culture. Although inactive in cells under normal conditions, the CHOP gene is markedly induced by a variety of cellular stresses, including nutrient deprivation and metabolic perturbations. These lead to accumulation of CHOP protein in the nucleus. Because cellular stress normally leads to growth arrest, we examined the implication of CHOP in this process. Microinjection of CHOP expression plasmids into NIH-3T3 cells blocked the cells from progressing through the cell cycle, measured by an attenuation in the fraction of cells incorporating BrdU, an S-phase marker. The precise point in the cell cycle at which CHOP acts was mapped by microinjection of bacterially expressed CHOP protein into synchronized cells-this blocked the cells from progressing from $G_{1}$ to $S$ phase. This effect of CHOP was observed only when the protein was introduced early after serum stimulation suggesting that CHOP works at or around the so-called $G_{1} / S$ checkpoint. CHOP dimerizes with other C/EBP proteins and the CHOP-C/EBP dimers are directed away from "classical" C/EBP sites recognizing instead unique "nonclassical" sites. Mutant forms of the CHOP protein that lack the leucine zipper dimerization domain or the unusually structured basic region, potentially involved in DNA binding, fail to induce growth arrest. A tumor-specific form of CHOP, TLS-CHOP, that has been found so far exclusively in the human adipose tissue tumor myxoid liposarcoma, fails to cause growth arrest and furthermore interferes with the ability of normal CHOP to induce growth arrest. CHOP has been shown recently to be markedly inducible by nutritional deprivation of cells. This suggests that CHOP may play a role in an inducible growth arrest pathway that is triggered by metabolic cues and is of particular importance in adipose tissue-an organ that undergoes marked changes in its metabolic activity. Blocking of this pathway by TLS-CHOP may play a mechanistic role in the establishment of myxoid liposarcoma.
\end{abstract}

[Key Words: Adipose tissue; cell cycle checkpoints; transcription factors; myxoid liposarcoma; DNA damage]

Received November 2, 1993; revised version accepted December 29, 1993.

Cells from organisms diverse as yeast and mammals share the capacity of responding to adverse growth conditions with a programmed block in progression through the cell cycle (Hartwell and Weinert 1989; Pardee 1989). Depending on the nature of the stressful condition, arrest may occur either before replication of cellular DNA (S phase) or prior to segregation of the genetic material during mitosis. One of the most potent inducers of this arrest process is the introduction of modifications in the structure of the DNA molecules (DNA damage), by either nutritional [e.g., $N$ (phosphoracetyl)-L-asparatate (PALA)-induced interference with purine metabolism], chemical (e.g., alkylating agents), or physical means (e.g., ionizing irradiation and UV light). The physiological im-

\footnotetext{
${ }^{3}$ Present address: Skirball Institute of Biomolecular Medicine, New York University Medical Center, New York, New York 10016 USA.

${ }^{4}$ Corresponding author.
}

portance of inducible growth arrest in response to DNA damage is demonstrated by the consequences of defects in this pathway. In yeast, mutations in the rad 9 gene impair the ability of irradiated cells to undergo $G_{2} / M$ arrest. $\operatorname{Rad} 9$ mutant yeast are viable under normal conditions but exhibit severe loss of genetic material and markedly reduced viability when challenged with ionizing irradiation (Weinert and Hartwell 1988). In humans with the hereditary disorder ataxia-teleangiectasia, cultured fibroblasts following irradiation, exhibit decreased ability to undergo inducible $G_{1} / S$ arrest and decreased viability compared with normal cells (Painter and Young 1980). The phenotype is further associated with a markedly increased incidence of a variety of tumors in these patients (McKinnon 1987). It is thought that the capacity to induce growth arrest in response to conditions that cause DNA damage arose from the advantages of delaying replication of defective DNA templates until the 
damage has been repaired $\left(\mathrm{G}_{1} / \mathrm{S}\right.$ arrest $)$ and delaying segregation of sister chromatids until DNA breaks, which would lead to loss of genetic material, have been corrected $\left(G_{2} / M\right.$ arrest; for review, see Hartwell 1992).

The molecular mechanisms that lead to growth arrest in response to DNA damage are not well understood. In mammalian cells the nuclear protein p53 appears to play an important role in $\mathrm{G}_{1} / \mathrm{S}$ arrest in response to ionizing irradiation (Kastan et al. 1992; Kuerbitz et al. 1992). Cells from patients with ataxia-teleangiectasia exhibit defective activation of the $\mathrm{p} 53$ protein in response to ionizing irradiation, and this defect is correlated with noninducibility of genes normally activated by p53 (Kastan et al. 1991). p53 appears to mediate growth arrest in response to other stimuli as well; treatment of normal growing cells with PALA, a specific inhibitor of uridine biosynthesis, leads to rapid growth arrest but sustained viability of normal cells in a $G_{0}$ resting state. However, cells with mutant p53 genes fail to arrest in response to PALA treatment and therefore die. The few surviving cells exhibit a marked increase in the rate of gene amplification, which leads to, among other things, amplification of the CAD gene and acquired resistance to the effects of PALA (Livingston et al. 1992; Yin et al. 1992). This important experiment suggests that regulatory pathways involved in inducible growth arrest play an important role in maintaining the integrity of the genome and that defects in these pathways may be responsible for the genomic instability of cancer cells (Hartwell 19921.

In spite of the pivotal role p53 plays in inducible growth arrest under some circumstances, there are reasons to believe that other pathways mediating DNA damage-inducible growth arrest may also exist. Growth arrest by p 53 occurs during the $\mathrm{G}_{1} / \mathrm{S}$ transition at the so-called restriction point (Lin et al. 1992). Ionizing irradiation, on the other hand, delays progression through the $G_{1} / S$ phase at more than one point; for example, delay can also be seen to occur in cells that have already passed the restriction point and have begun to synthesize DNA (Hartwell 1992). The $G_{2} / M$ transition that is also blocked in response to DNA damage in mammalian cells is not mediated by p53 (Kastan et al. 1991). These observations suggest the existence of alternative pathways for eliciting growth arrest. We focused on one such alternative pathway.

CHOP ( $\mathrm{C} / \mathrm{EBP}$ homologous protein, also known as GADD 153) is a nuclear protein that is markedly induced in response to DNA-damaging agents such as the alkylating compound methyl methanesulfonate (MMS) and to a lesser degree by ionizing irradiation and UV light (Fornace et al. 1989; Ron and Habener 1992). CHOP is also induced during the in vitro differentiation of 3T3-L1 cells to adipocytes, an event associated with acquisition of a growth-arrested state (Ron and Habener 1992). CHOP dimerizes with transcription factors from the $\mathrm{C} / \mathrm{EBP}$ family to form a dimeric complexes capable of binding in vitro to certain "nonclassical" CCAAT/enhancer-binding protein (C/EBP) sites (A. Crozat, $\mathrm{H}$. Wu, J. Habener, and D. Ron, unpubl.). One member of this family, $\mathrm{C} / \mathrm{EBP} \alpha$, has been demonstrated to play a role in regulating cellular proliferation during adipocytic differentiation (Umek et al. 1991; Freytag and Geddes 1992; Lin and Lane 1992). These findings suggested to us that CHOP may play a role in the growth arrest observed under these conditions. Additional evidence of a role for CHOP in regulating cellular proliferation is provided by the observation that in myxoid liposarcoma, a tumor of human adipose tissue, a specific chromosomal translocation results in the expression of a fusion protein between CHOP and the amino terminus of a novel RNAbinding protein, TLS (translocated in liposarcoma) (Åman et al. 1992; Crozat et al. 1993; Rábitts et al. 1993). The TLS-CHOP fusion protein can cause transformation of NIH-3T3 cells $(\mathrm{H}$. Zinszner and D. Ron, unpubl.), supporting a direct role for $\mathrm{CHOP}$ in growth regulation. The coincidence of CHOP induction with a variety of conditions that are also associated with growth arrest and the constitutive presence of an abnormal CHOP protein in myxoid liposarcoma cells led us to speculate that CHOP may play a role in growth arrest and that this role would not be shared by the tumor associated form of CHOP.

\section{Results}

Expression of wild-type CHOP protein inhibits BrdU incorporation

CHOP mRNA and protein are virtually undetectable in continuously dividing cells. However a variety of growth-arresting stimuli induce the expression of the protein (Fornace et al. 1989; Ron and Habener 1992). To study the phenotypic changes associated with the expression of CHOP protein we attempted to select stable clones that would constitutively express CHOP. Cotransfection of the selectable marker neo, along with an expression plasmid for CHOP into mouse fibroblastic cells, led to the emergence of very few G418-resistant colonies. Western blot analysis of the colonies showed no expression of CHOP protein. However, when an expression plasmid encoding a mutant form of $\mathrm{CHOP}$, which is lacking the leucine zipper dimerization domain (CHOP-LZ ${ }^{-}$; Ron and Habener 1992), was used, three times more G418 resistant colonies were observed and many of those expressed the mutant CHOP protein (similar results have been obtained by Zhan et al. 1994). We interpreted these result to suggest that expression of wild-type $\mathrm{CHOP}$ was selected against during the elaboration of G418-resistant colonies and that the $\mathrm{LZ}^{-} \mathrm{mu}-$ tant form of the protein was inert in this respect.

To determine the basis for the selection against CHOP-expressing cells we microinjected expression plasmids encoding wild-type CHOP and the $\mathrm{LZ}^{-}$mutant form of the protein into NIH-3T3 cells and determined the ability of the CHOP-expressing cells to take up bromodeoxyuridine (BrdU), a marker for the $S$ phase of the cell cycle. Microinjected cells exhibited high level of nuclear CHOP staining and the ratio of the number of microinjected to immunoreactive cells $(\sim 25 \%-50 \%)$ was 
no different in the cells expressing the wild-type or mutant forms of the protein. This indicates that expression of CHOP is not in and of itself toxic to the cells over the time period studied. However, when the uptake of BrdU was compared between the CHOP-expressing cells and adjacent cells on the coverslip that were not expressing $\mathrm{CHOP}$, a marked reduction in BrdU incorporation was observed in the former (Fig. 1). Cells expressing the $\mathrm{LZ}^{-}$ mutant form of CHOP had levels of incorporation of BrdU that were no different from uninjected cells (Fig. 1).

To maximize our ability to detect the inhibitory effect of CHOP, we arrested the cells in $\mathrm{G}_{0}$, by serum starvation, prior to microinjecting them with the CHOP-expression plasmids. Twenty-four hours after injection the cells were switched to media containing $20 \%$ fetal calf serum to stimulate progression through the cell cycle and BrdU incorporation was evaluated after another 18 hr (see Fig. 1B). This experimental design was chosen because it led to very high BrdU incorporation in a synchronized population of control cells exiting $G_{0}$ at a defined time point. However, inhibition of BrdU incorporation by $\mathrm{CHOP}$ was observed as early as $24 \mathrm{hr}$ after injection of the CHOP-expression plasmids (Figs. 3 and 4 , below) and was observed in both asynchronously growing cells (data not shown) and in cells synchronized by release from low serum $G_{0}$ arrest (Fig. 1). These results are most consistent with the possibility that the presence of CHOP protein prevents these cells from progressing through the cell cycle and eventually inhibits their ability to reach S phase and incorporate BrdU.

To determine whether the inhibitory effect of CHOP on cell growth is a feature of cell types other than NIH3T3 we performed the same experiment in HeLa cells and in a clone of 3T3 cells transformed by the hamster papilloma virus middle $\mathrm{T}$ antigen (Courtneidge et al. 1991). Wild-type CHOP, but not the $\mathrm{LZ}^{-}$mutant, inhibited BrdU incorporation in all three cells lines tested (Fig. 1B|. Both the HeLa cells and the transformed NIH-3T3 cells are not fully driven to $\mathrm{G}_{0}$ by low serum, a measure of their transformed phenotype. We conclude, therefore, that the ability of CHOP to arrest cells extends to cells other than serum-responsive NIH-3T3.

\section{CHOP arrests cells at the $G_{1} / S$ boundary}

The observation that serum-starved cells microinjected with CHOP-expression plasmid were incapable of incorporating BrdU within the first $24 \mathrm{hr}$ of serum stimulation (i.e., within the first cycle following release from $\mathrm{G}_{0}$ ) strongly favored arrest at the $\mathrm{G}_{1} / \mathrm{S}$ boundary. To conclusively identify a point in the cell cycle in which CHOP acts, circumventing the difficulty associated with the inherent latency of plasmid microinjection experiments, we injected cells with purified CHOP proteins. Serum-starved NIH-3T3 cells were injected with bacterially expressed glutathione $S$-transferase (GST) fusion proteins of wild-type and $\mathrm{LZ}^{-}$mutant forms of CHOP. The injections were performed at different time points with respect to the initiation of a 24-hr serum stimulation and BrdU incorporation period (for details on exper- imental design, see Fig. 2). When wild-type CHOP was injected at the time of serum stimulation, inhibition of BrdU incorporation reached a level of $60 \%$ (Fig. 2). The $\mathrm{LZ}^{-}$mutant $\mathrm{CHOP}$ was not inhibitory. When injection was delayed until $6 \mathrm{hr}$ after serum stimulation the inhibition of BrdU incorporation fell to $20 \%$ and was reduced even further when injection was delayed until $16 \mathrm{hr}$ after serum stimulation.

These results argue strongly that $\mathrm{CHOP}$ protein inhibits the $G_{1} / S$ transition. The inability of CHOP to cause growth arrest when injected late in $G_{1}$ suggests that the protein exerts its effect relatively early, perhaps at or near the "restriction point" (Pardee 1989). The presence of near normal BrdU incorporation in cells injected just prior to BrdU labeling indicates that the presence of CHOP is not, in and of itself, inhibitory to DNA synthesis. The differences in level of inhibition between the experiments in which CHOP-expression plasmids were injected $(\sim 80 \%)$ versus those observed when bacterially expressed protein was injected $(\sim 60 \%)$ may be due to less than full activity of the bacterial-expressed protein.

\section{CHOP proteins bearing mutations in the basic region fail to induce growth arrest}

In vitro studies have shown that $\mathrm{CHOP}$ can serve as both an inhibitor of DNA binding by C/EBP proteins, with respect to certain classical C/EBP sites (Ron and Habener 1992) and as an entity capable of binding as a dimer with C/EBP proteins to certain unique nonclassical C/EBP sites (A. Crozat, H. Wu, J. Habener, and D. Ron, unpubl.). We therefore wanted to know which of the two functions of CHOP is relevant to its growtharresting properties. Truncation of the leucine zipper inactivates both functions of the protein and abolishes the ability to induce growth arrest (Figs. 1 and 2). To create mutations that might interfere with the ability of CHOP-C/EBP dimers to bind nonclassical target sequences, without affecting the ability of CHOP to inhibit C/EBP binding to "classical" sites, we constructed expression plasmids encoding $\mathrm{CHOP}$ proteins that bear deletions in the CHOP basic region. These proteins failed to bind DNA in vitro and, when expressed in cells, localized poorly to the nucleus [detailed analysis of these mutants will be presented elsewhere (A. Crozat, H. Wu, J. Habenes, and D. Ron, unpubl.)]. This defect in nuclear localization rendered interpretation of the significance of any defective phenotype the mutant proteins might have impossible. We therefore introduced a heterologous nuclear localization signal into the mutant proteins (and as a control also into the wild-type protein) and studied the effect of microinjection of expression plasmids encoding these $\mathrm{BR}^{-}$mutants on BrdU incorporation. Figure 3A show that all forms of the protein localize to the nucleus and that addition of a heterologous nuclear localization signal does not effect the ability of the wild-type protein to inhibit BrdU incorporation (Fig. 3B, cf. WT to WT-NLS). Microinjection of expression plasmids encoding the $\mathrm{BR}^{-}$mutant $\mathrm{CHOP}$ proteins mutB-NLS and mutCb-NLS revealed that expression of these proteins did not result in inhibition of 
A

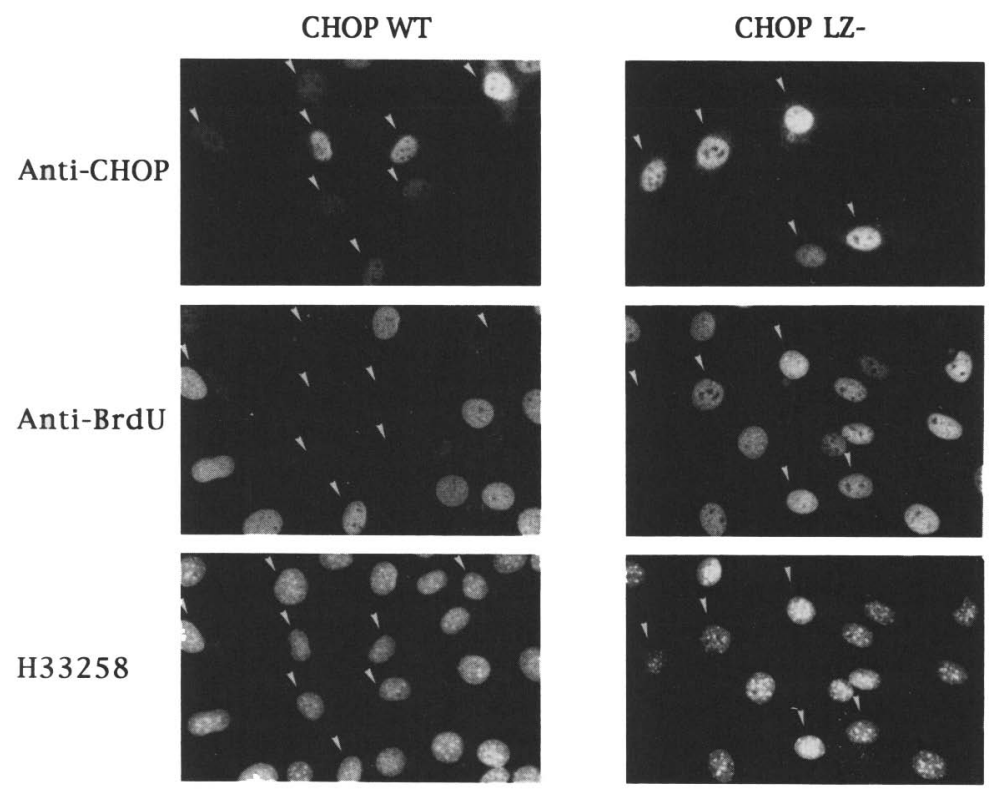

Figure 1. Measurement of the ability of wild-type and leucine-zipper minus mutant $\mathrm{CHOP}$ protein to block BrdU incorporation in serum-stimulated cells. $(A)$ Serumstarved cells growing on coverslips were microinjected with expression plasmids encoding wild-type CHOP (CHOP-WT) and a mutant version of $\mathrm{CHOP}$ that is missing the leucine zipper dimerization domain (CHOP-LZ $\left.{ }^{-}\right)$. The cells were stimulated with $20 \%$ FCS for $24 \mathrm{hr}$ and were treated with BrdU for the last $6 \mathrm{hr}$. Cells were then fixed and stained simultaneously with antisera to CHOP and BrdU. The DNA binding dye $\mathrm{H} 33258$ was included to allow visualization of all the nuclei in a given field. The photomicrographs show the staining of CHOP, BrdU, and H33258 in the same microscope field, visualized by using different light wavelength filters. The position of the cells immunoreactive with the CHOP an. tiserum is indicated by the small white arrowheads. Most of the cells positive for the wild-type but not mutant forms of $\mathrm{CHOP}$ fail to incorporate BrdU. $(B)$ Quantitation of inhibition of BrdU incorporation in the cells staining positive for CHOP proteins. The mean inhibition in two representative experiments and the range is shown (for details, see Materials and methods). The experimental outline is shown schematically below the bar diagram. (3T3) NIH-3T3 cells; (3T3HaMT) NIH-3T3 cells transformed with hamster polyoma virus middle $T$ antigen.

\section{B}
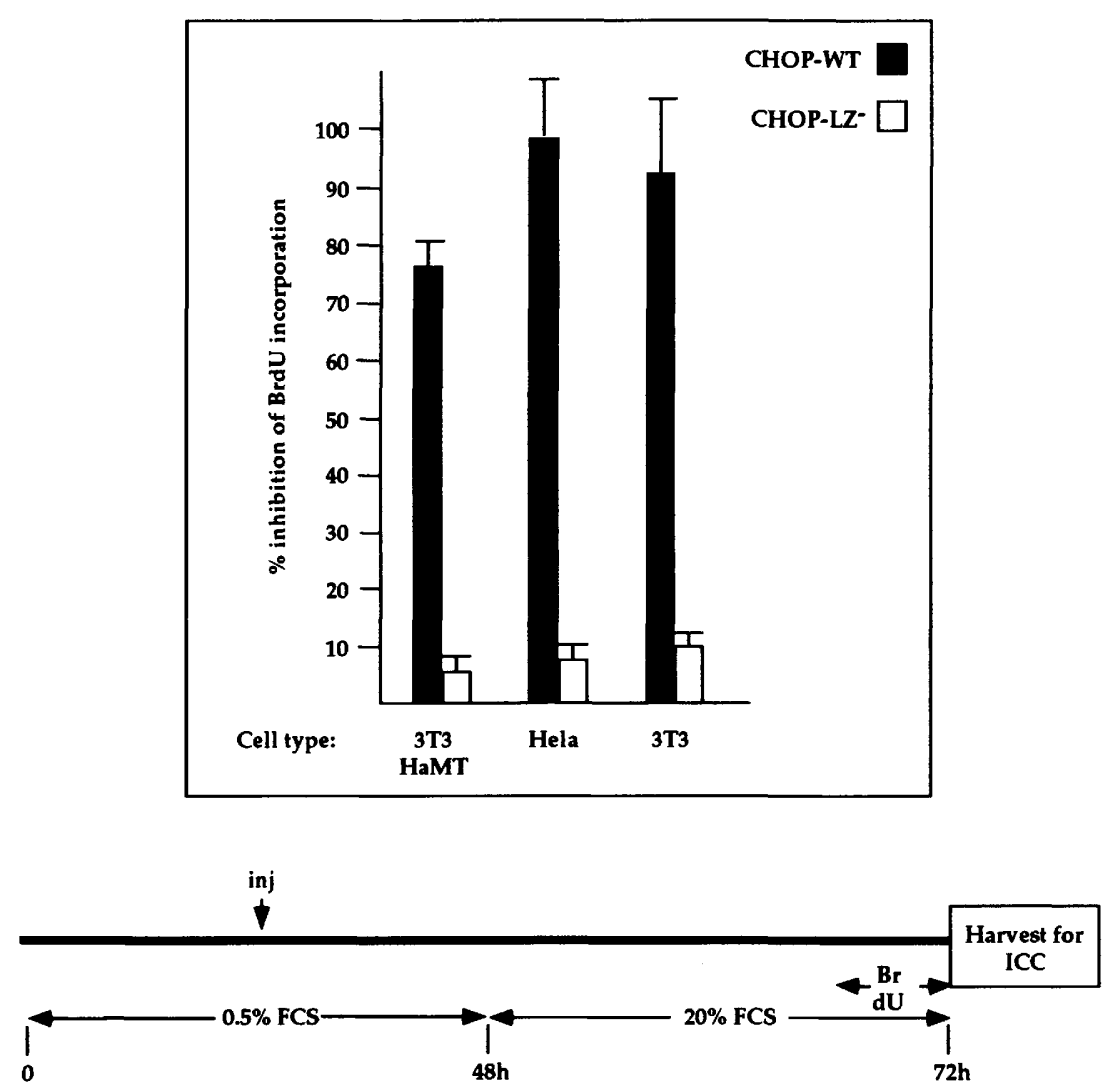

BrdU incorporation (Fig. 3B). This result indicates that growth arrest by CHOP is dependent on the integrity of the basic region and is not merely the consequence of expression of large quantities of an inert C/EBP-type leucine zipper protein. It suggests therefore that the positive effects of CHOP, rather than its inhibitory effects on 
A
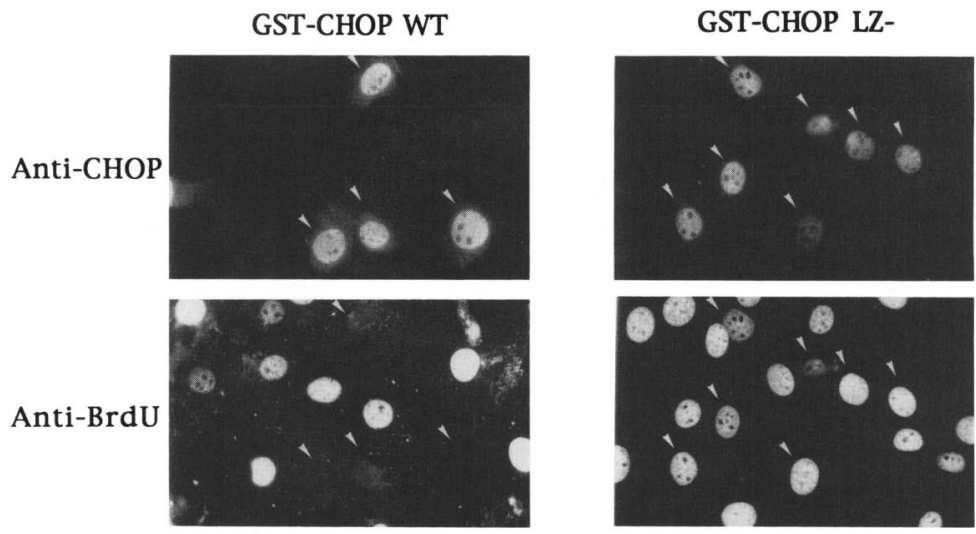

H33258
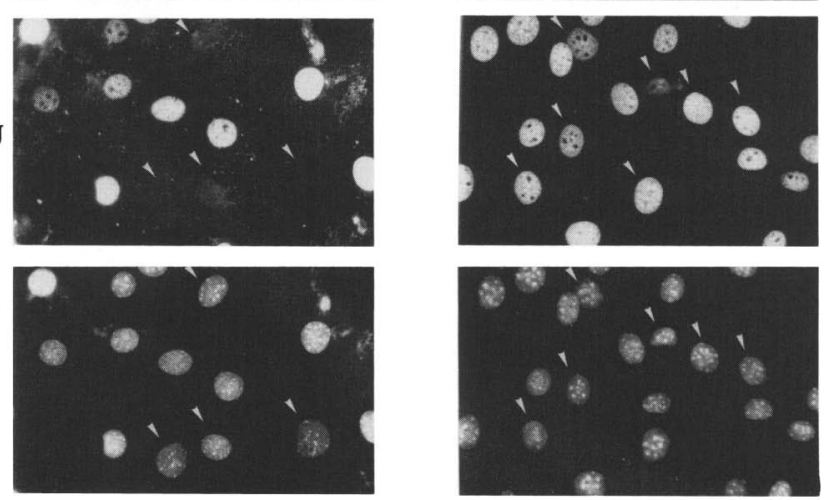

B
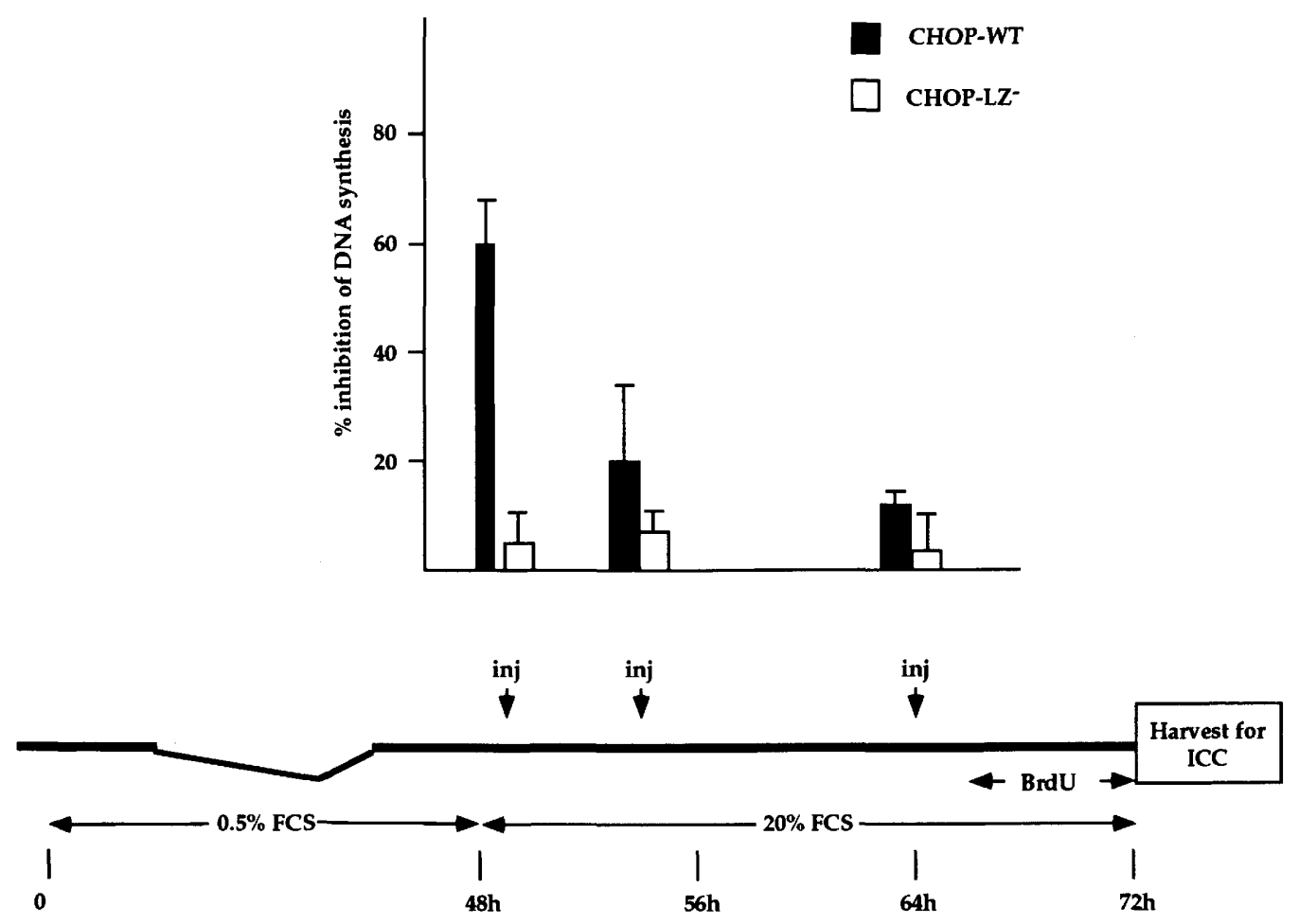

Figure 2. CHOP arrests cells at the $\mathrm{G}_{1} / \mathrm{S}$ phase. Serum-starved NIH-3T3 cells were microinjected with bacterially expressed $\mathrm{CHOP}-$ GST fusion protein at various time intervals after serum stimulation. The cells were labeled with BrdU and stainea with antisera to CHOP and BrdU. $(A)$ CHOP, BrdU, and nuclear DNA are visualized in cells injected at the time of serum stimulation. The position of the cells immunoreactive with the CHOP antiserum is indicated by the small white arrowheads. Microinjected proteins are visualized in the nucleus as late as $24 \mathrm{hr}$ after injection. A decreased fraction of cells injected with the wild-type CHOP protein incorporate BrdU. $(B)$ Quantitation of inhibition of BrdU incorporation in the cells injected at different time points after serum stimulation. The mean and range of inhibition in two representative experiments is shown. 

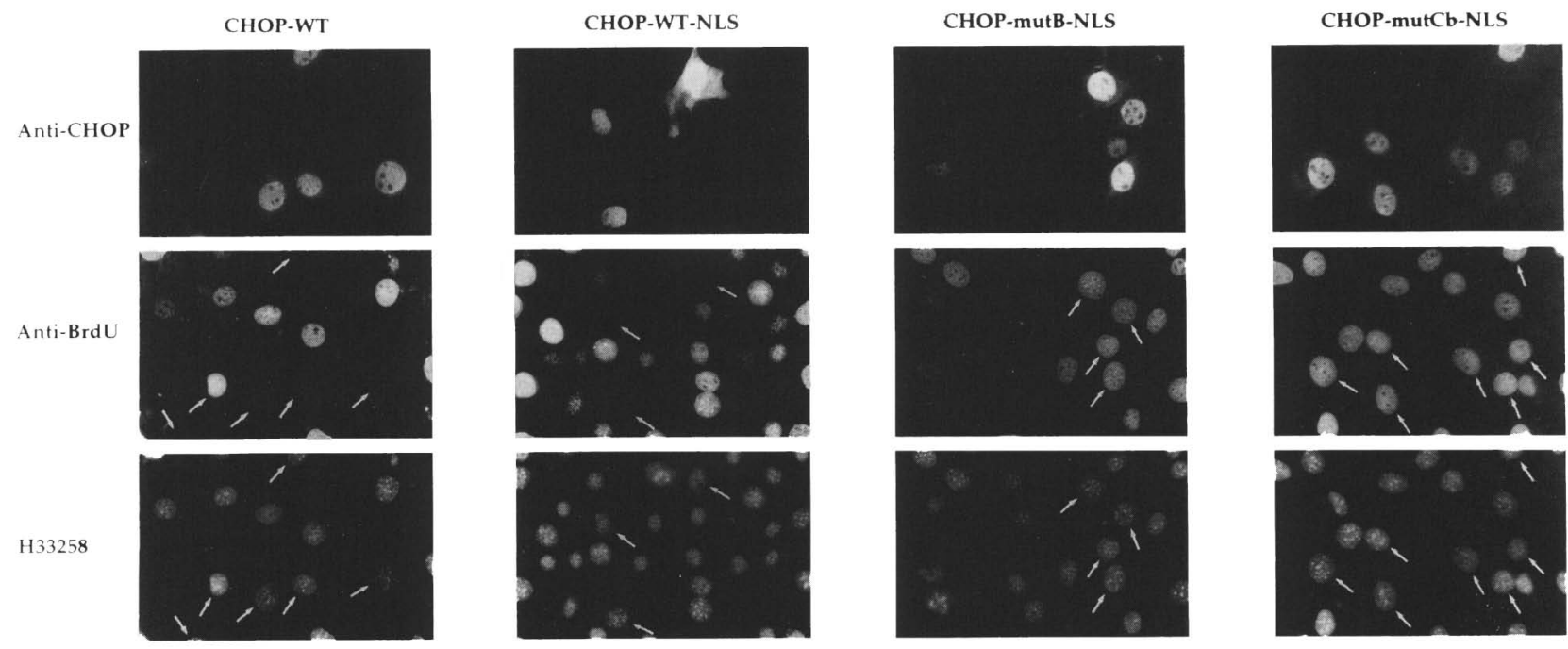

Figure 3. Measurement of the ability of wildtype and basic region mutant CHOP proteins to block the $\mathrm{G}_{1} / \mathrm{S}$ transition in NIH-3T3 cells. (A) NIH-3T3 cells growing on coverslips and microinjected with expression plasmids encoding wild-type CHOP (CHOP-WT), wild-type CHOP with a heterologous nuclear localization signal (CHOP-WT-NLS) and basic region deletion mutant forms of $\mathrm{CHOP}$ with a heterologous NLS (CHOP-mutB-NLS and CHOPmutCb-NLS) were treated with BrdU for $6 \mathrm{hr}$, fixed, and stained simultaneously with antisera to CHOP and BrdU. The DNA-binding dye $\mathrm{H} 33258$ was included to allow visualization of all the nuclei in a given field. The photomicrographs show the staining of CHOP, BrdU, and $\mathrm{H} 33258$ in the same microscope field, visualized by using different fluorescent filters. The position of CHOP-positive cells is indicated by the arrows. Cells positive for the wild-type but not mutant forms of CHOP fail to incorporate BrdU. $(B)$ Quantitation of the growth inhibition by $\mathrm{CHOP}$ proteins. The mean and range of inhibition of BrdU incorporation in two representative experiments is shown. The experimental design is shown schematically below the bar diagram.
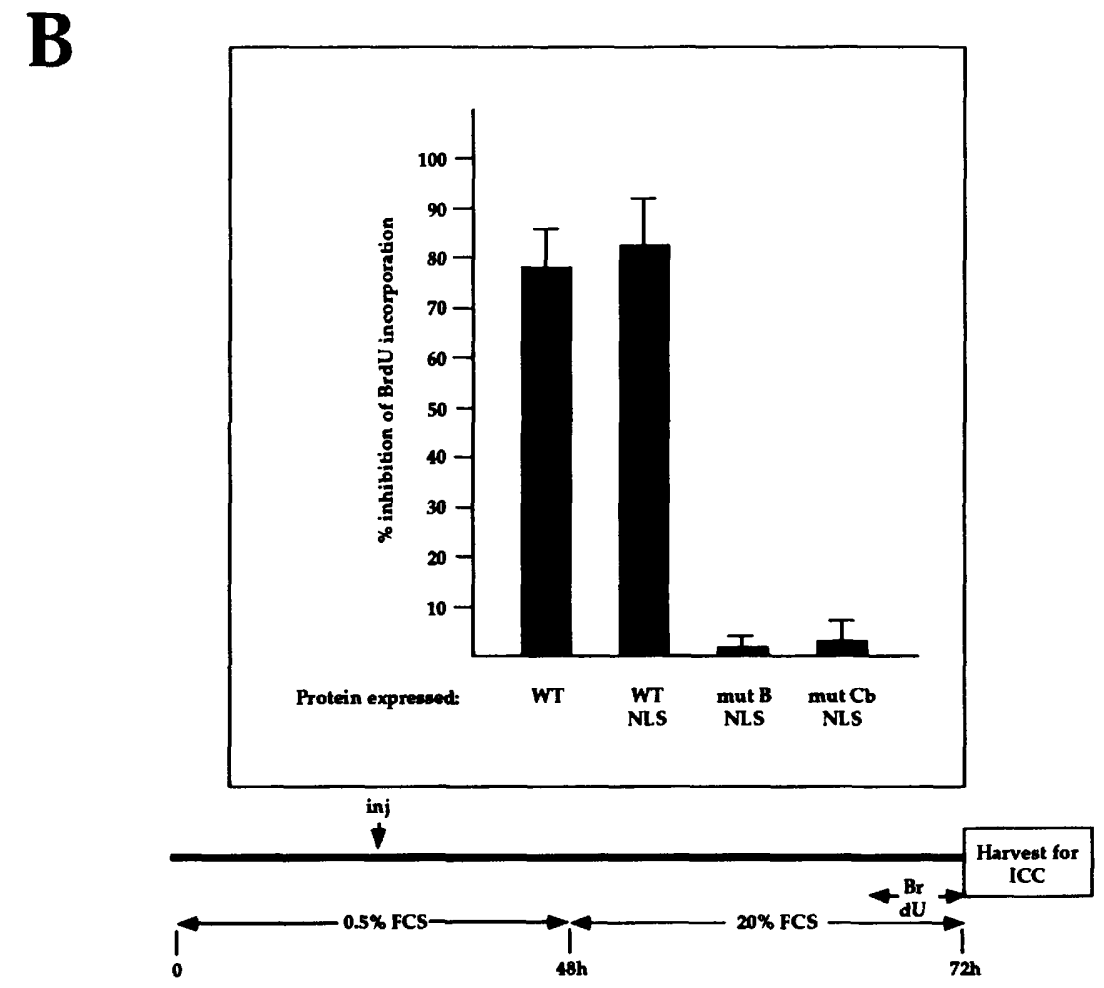

C/EBP proteins, are relevant to the growth arrest phenotype.

Expression of the tumor-specific form of $C H O P$, TLS-CHOP, does not lead to growth arrest

Human myxoid liposarcoma cells constitutively express a fusion protein between $\mathrm{CHOP}$ and the amino terminus of an RNA-binding protein, TLS. The architecture of the encoded fusion protein is such that all of the CHOPcoding region is translated in the TLS-CHOP mRNA and CHOP constitutes the carboxyl terminus of the fusion protein (Fig. 4A). TLS-CHOP localizes in the nucleus in a manner that is indistinguishable from that of CHOP (Crozat et al. 1993). Furthermore, whereas CHOP expression is not tolerated by proliferating NIH-3T3 cells, we had no difficulty in stably expressing TLSCHOP (H. Zinszner and D. Ron, data not shown). Con- 
A

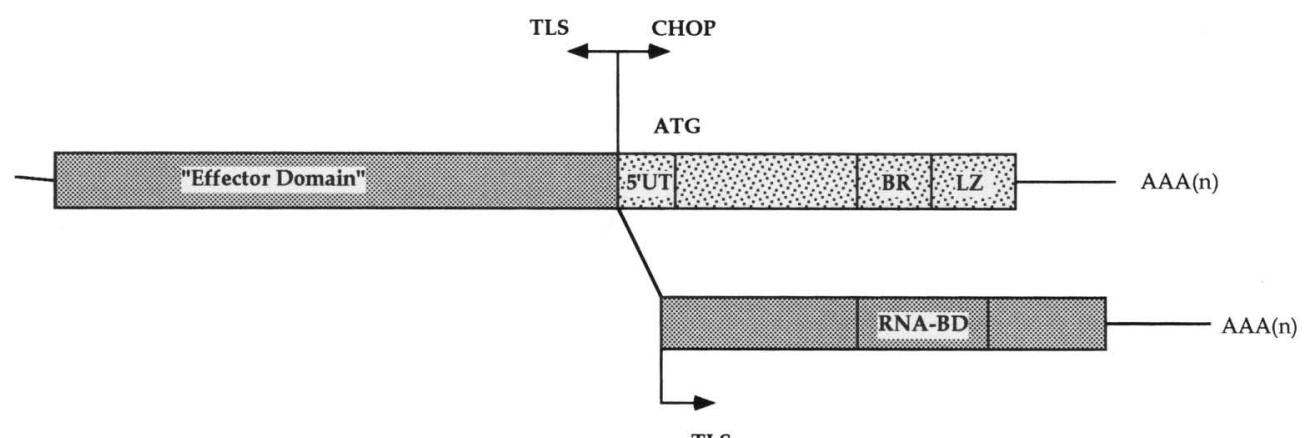

TLS

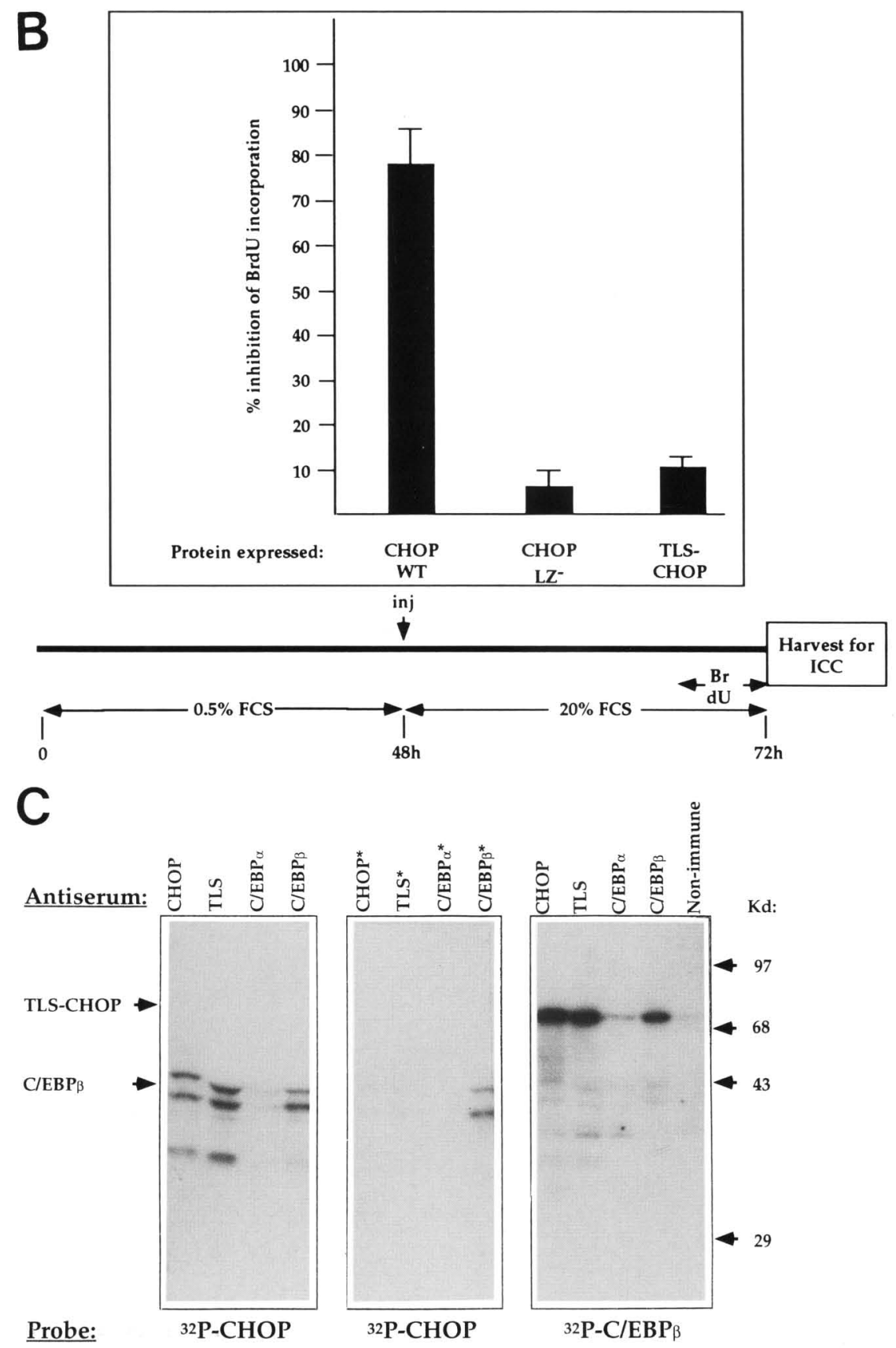

Figure 4. The myxoid liposarcoma-specific oncoprotein TLS-CHOP fails to induce growth arrest yet is capable of dimerizing with C/EBP proteins. (A) A schematic diagram of the structure of TLS-CHOP. Note that all the CHOP coding region is included in the fusion protein. (B) NIH-3T3 cells microinjected with wild-type $\mathrm{CHOP}, \mathrm{CHOP}$ $\mathrm{LZ}^{-}$, and TLS-CHOP plasmids were assayed for their ability to incorporate BrdU. (C) Coimmune preciptation of TLS-CHOP with $\mathrm{C} / \mathrm{EBP} \beta$ from nuclear extracts of $\mathrm{myx}$ oid liposarcoma cells. Nuclear extracts were precipitated with the antisera indicated above the autoradiograph. The complexes in the immunoprecipitates were dissociated by SDS and heating, fractionated on an SDS gel, and transferred to nitrocellulose filters by Western blotting; the blot was probed a ${ }^{32}$ P-labeled dimerization probe in a zipper blot assay. The left and central blots were reacted with a CHOP dimerization probe; the blot on the right was reacted with a $\mathrm{C} / \mathrm{EBP} \beta$ probe. In the central blot the dimerizing proteins were dissociated by means of SDS and Triton treatment of the nuclear extracts prior to immunoprecipitation and zipper blotting. 
sistent with this observation, microinjection of TLSCHOP expression plasmid had no effect on BrdU incorporation (Fig. 4B). This dichotomy in the behavior of the two proteins prompted us to further investigate the structure/function relationships of CHOP and TLSCHOP.

To exclude the possibility that failure of TLS-CHOP to arrest cells was due to defective dimerization we studied the dimerization properties of TLS in vivo. Proteins from nuclear extracts of the TLS-CHOP-containing myxoid liposarcoma cell line 1955/91 were immunoprecipitated with antiserum directed against CHOP, TLS, $\mathrm{C} / \mathrm{EBP} \alpha$, and $\mathrm{C} / \mathrm{EBP} \beta$. The immunoprecipitated proteins were detected in a zipper blot assay using ${ }^{32} \mathrm{P}$-labeled CHOP or C/EBP $\beta$ dimerization probes (Ron and Dressler 1992). The CHOP zipper probe recognizes an indistinguishable set of proteins in the CHOP, TLS, and C/EBPB immunoprecipitates. The mobility of the detected proteins is most consistent with the three translation forms of C/EBP (Fig. 4C). It should be noted that the smallest form of C/EBP $\beta$ [known as LAP inhibitory protein (LIP) (Descombes and Schibler 1991)], is absent from the $\mathrm{C} / \mathrm{EBP} \beta$ immunoprecipitate. This is attributable to the fact that the C/EBP $\beta$ antiserum used is directed against a peptide sequence in the amino terminus of the protein that is absent in the LIP form of C/EBP $\beta$. All three forms of $\mathrm{C} / \mathrm{EBP} \beta$ are present in the TLS and CHOP precipitates, consistent with the interpretation that all of them are capable of dimerizing with TLS-CHOP. The CHOP zipper probe failed to detect the larger TLS-CHOP protein, consistent with our observation that CHOP does not form stable homodimers (A. Crozat, $\mathrm{H}$. Wu, J. Habener, and D. Ron, unpubl.). When the C/EBP $\beta$ zipper probe was used to detect dimerizing species in the identical set of immunoprecipitates, the large TLS-CHOP protein was easily detectable in the lanes precipitated with the TLS, CHOP, and C/EBP $\beta$ sera. In addition to TLS - CHOP, the C/EBP $\beta$ probe detected C/EBP $\beta$, as well as other unidentified weaker bands. The C/EBP $\alpha$ immunoprecipitate contained very little detectable activity, consistent with the fact that the 1955/91 cell line has very little $\mathrm{C} / \mathrm{EBP} \alpha$ protein (D. Ron, unpubl.). To confirm that TLS-CHOP and C/EBP $\beta$ are specifically coimmune precipitating as a dimeric complex, we treated the nuclear extracts with harsh conditions $10.1 \%$ SDS, $1 \%$ Triton/ prior to performing the immunoprecipitations and zipper blot. This led to the dissociation of the dimers and the immunoprecipitates contained therefore only the protein primarily recognized by the antiserum-C/EBP $\beta$ is no longer present in significant amounts in the CHOP or TLS immunoprecipitates (Fig. 4C, middle panel). From this set of experiments we concluded that the inability of TLS-CHOP to arrest cells is not attributable to a defect in dimerization or sequestration of the protein in an inaccessible compartment.

TLS-CHOP suppresses the ability of CHOP to induce growth arrest

TLS-CHOP is transforming in a dominant fashion- nontransformed NIH-3T3 cells expressing TLS-CHOP acquire a transformed phenotype $(H$. Zinszner and $D$. Ron, unpubl.). One mechanism that may contribute to its transforming activity and would be consistent with the inability of TLS-CHOP to arrest cells is an interference with function of CHOP by TLS-CHOP. To address this possibility we comicroinjected TLS-CHOP with CHOP-expression plasmids into NIH-3T3 cells and measured the inhibition of BrdU incorporation. Coexpression of TLS-CHOP led to a $50 \%$ attenuation in the ability of CHOP to induce a decrease in BrdU incorporation in cells (Fig. 5). The inhibition was dose dependent, requiring at least a twofold excess of TLS-CHOP expression plasmid over that of CHOP for the effect to be apparent. This stochiometry is not surprising in view of the fact that the TLS gene is very actively transcribed in the myxoid liposarcoma cells and the level of TLS-CHOP in these cells is significantly higher than levels attained by CHOP even under maximal stimulation [Crozat et al. 1993 [Fig. 1B therein)].

The inhibitory effect of TLS-CHOP is specific for CHOP-mediated growth arrest. Other C/EBP proteins, such as $\mathrm{C} / \mathrm{EBP} \alpha$ and $\mathrm{C} / \mathrm{EBP} \beta$, that also induce growth arrest when expressed at high levels in NIH-3T3 cells (also see Umek et al. 1991), are not inhibited by TLS CHOP (Fig. 5). Because the CHOP antiserum recognizes CHOP and TLS-CHOP indistinguishably in the immunofluorescent assay and because of the high levels of endogenous TLS (precluding the use of the anti-TLS serum to detect TLS-CHOP), we were unable to estimate the level of expression of both proteins separately in the microinjected cells. However, myxoid liposarcoma cells can be induced to coexpress CHOP and TLS-CHOP (Crozat et al. 1993), demonstrating that there is no inherent incompatibility in the expression of the two proteins. By staining an identical set of comicroinjected cells with antisera to $\mathrm{CHOP}$ and $\mathrm{C} / \mathrm{EBP} \alpha$ or $\mathrm{C} / \mathrm{EBP} \beta$ proteins, we determined that TLS-CHOP does not have a major effect on the expression of comicroinjected plasmids (data not shown). We therefore believe that the attenuation of CHOP-mediated growth arrest by TLS is not attributable to a nonspecific suppression of the level of CHOP protein in the microinjected cells but, rather, is attributable to a specific interference with an important function of wild-type CHOP. This experiment thus demonstrates the presence of a specific dominant negative effect of TLS-CHOP on the ability of CHOP, but not $\mathrm{C} / \mathrm{EBP} \alpha$ and $\mathrm{C} / \mathrm{EBP} \beta$, to induce growth arrest in microinjected cells.

\section{Discussion}

Our experiments show that expression of the DNA damage-inducible protein $\mathrm{CHOP}$ in cells causes growth arrest. Several observations led us to believe that this effect of CHOP reflects a physiological role, as opposed to being the result of an unphysiological experimental system. Expression of CHOP is strongly selected against during the elaboration of clones of cells cotransfected with CHOP-expression plasmid and a selectable marker. 


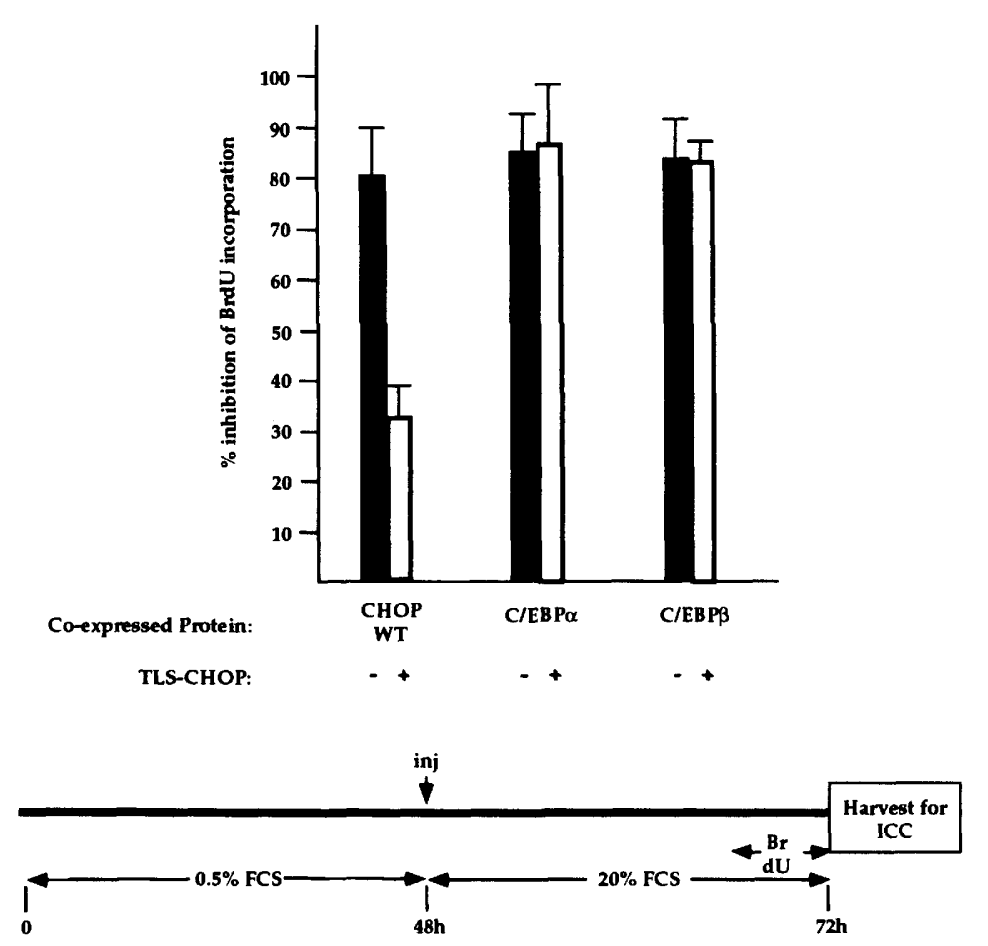

Figure 5. TLS-CHOP attenuates the ability of CHOP, but not $\mathrm{C} / \mathrm{EBP} \alpha$ and $\mathrm{C} / \mathrm{EBP} \beta$ to inhibit growth. NIH$3 \mathrm{~T} 3$ cells were injected with a TLS-CHOP-expression plasmid and expression plasmids encoding $\mathrm{CHOP}$, $\mathrm{C} / \mathrm{EBP} \alpha$, and C/EBP $\beta$. The mean growth inhibition and range in two experiments is shown. The inhibition of BrdU incorporation observed in the absence of TLSCHOP was significantly greater than that observed in its presence in the case of CHOP but not in the case of $\mathrm{C} / \mathrm{EBP} \alpha$ - and $\mathrm{C} / \mathrm{EBP} \beta$-injected cells.
Whereas the level of expression of CHOP in microinjected cells is likely to be very much higher than the level attained under physiological conditions, the stably transfected cells were never seen to express detectable amounts of wild-type CHOP protein. Thus, the striking inhibition of growth observed in short-term experiments with microinjected cells parallels the effects of much smaller quantities of the protein expressed over longer periods of time in the stable transfectants, indicating that, given enough time, even small amounts of $\mathrm{CHOP}$ contribute to growth arrest. The ability of CHOP to induce growth arrest is dependent on its ability to dimerize with other C/EBP proteins and on the intactness of the CHOP basic region. Furthermore, expression of TLS$\mathrm{CHOP}$, a protein identical to CHOP except for the presence of a large amino-terminal extension, does not lead to growth arrest. These latter findings argue strongly that the inhibitory effect of CHOP is unlikely to be attributable merely to the overexpression of an active protein interface that may serve to unphysiologically sequester some vital nuclear component. Instead, the observation that arrest was restricted to wild-type CHOP supports the notion that arrest is mediated by a highly specific signaling pathway that requires many facets of the CHOP protein.

In the microinjection assay, growth inhibition is detected by a diminished fraction of cells that enter $S$ phase (and thus incorporate BrdU). This may be attributable to arrest or delay in any point of the cell cycle. Using cells synchronized in $\mathrm{G}_{0}$ and stimulated with serum, we were able to concentrate on a defined segment of the cell cycle, the $\mathrm{G}_{0} / \mathrm{S}$ transition. CHOP protein exerts a potent inhibitory effect on cells traversing this segment. When the experiment was performed in cycling cells, which progress from mitosis directly to a growth phase and DNA synthesis without going into a $G_{0}$ state, a similar inhibitory effect was observed (data not shown). This suggests that $C H O P$ acts during the $G_{1} / S$ phase of the cell cycle (rather than merely inhibiting the egress from the quiescent $G_{0}$ phase). The inhibitory effect of $\mathrm{CHOP}$ was dependent on the presence of the protein early in $G_{1}$. If injection of CHOP protein was delayed as little as $6 \mathrm{hr}$ after serum stimulation, the inhibitory effect was markedly diminished (Fig. 2). This finding suggests that CHOP exerts its effect sometime before the $\mathrm{G}_{1} / \mathrm{S}$ "restriction point" (Pardee 1989). One way this might come about would be by interfering with the accumulation or function of a critical regulatory entity that signals progression through that phase of the cycle (e.g., a cyclin or a cyclin-dependent kinase). The observation that not all the CHOP-positive cells fail to incorporate BrdU is consistent with the idea that the inhibitory effect can be overcome by an excess of the functional target for $\mathrm{CHOP}$ action and that stochastic processes that regulate the amount of this putative target determine the susceptibility of any individual cell to the effects of CHOP.

The mechanism by which CHOP exerts its inhibitory effect on $G_{1} / S$ transition is not known. However, the observation that inhibition is dependent on both the dimerization domain and basic region of $\mathrm{CHOP}$ suggests that DNA binding may be involved in the inhibitory effect. It is noteworthy in this regard that we have recently found that CHOP-C/EBP heterodimers are capable of sequence-specific DNA binding and that the CHOP protein possesses powerful transcriptional activation potential (A. Crozat, H. Wu, J. Habener, and D. Ron, 
unpubl.). An attractive hypothesis is that DNA binding by CHOP alters the expression of critical target genes and that it is the activity of the products of these genes that mediates the growth arrest program. An alternative hypothesis in which DNA binding by CHOP directly inhibits the replication of the DNA template is contradicted by the observations that CHOP works early in $\mathrm{G}_{1}$ and not in the $S$ phase and that the presence of the $\mathrm{CHOP}$ protein in the nucleus is not in and of itself inhibitory to DNA replication. The hypothesized requirement for transcription and translation of the products of the putative CHOP target genes complicates somewhat the identification of the precise time point of $\mathrm{CHOP}$ action and we cannot exclude the possibility that $\mathrm{CHOP}$ arrests cells rather later in $G_{1}$ than our protein microinjection experiments would suggest. It is also important to point out that the microinjection experimental design used is best suited for studying the $G_{1} / S$ transition, and we did not address the possibility that CHOP may have addional effects at other stages of the cell cycle.

Our experimental results suggest that $\mathrm{CHOP}$ participates in an inducible $\mathrm{G}_{1} / \mathrm{S}$ checkpoint. $\mathrm{CHOP}$ is induced by some forms of cellular stress: alkylating agents such as MMS, glucose deprivation, and endogenous and exogenous toxins but is rather weakly induced by ionizing irradiation or UV light (Fornace et al. 1989; Chen et al. 1992; Ron and Habener 1992; Carlson et al. 1993). It is tempting to speculate that CHOP functions in one of several overlapping pathways that mediate $G_{1} / S$ delay in response to specific stressful events. Other contributors to a functionally similar checkpoint include a signaling pathway that is dependent on the activity of p53 and appears to be highly responsive to ionizing irradiation and UV light (Kastan et al. 1991, 1992). Ataxia-telangiectasia cells, which are defective in activating the p53dependent pathway, nonetheless are capable of inducing CHOP in response to MMS, albeit with decreased intensity (Kastan et al. 1992). In addition, preliminary evidence suggests that other DNA damage-inducible genes, such as GADD45 and GADD34, contribute in parallel to the growth arrest induced by CHOP. This latter conclusion is inferred from the observation that cotransfection of expression plasmids encoding these proteins together with $\mathrm{CHOP}$ causes a greater attenuation of stable colony formation than expression of any one protein alone (Zhan et al. 1994). These observations suggest the existence of overlapping pathways that mediate activation of an inducible $\mathrm{G}_{1} / \mathrm{S}$ checkpoint.

$\mathrm{CHOP}$ shares the ability to induce growth arrest with other members of the C/EBP family. The mechanism by which C/EBP proteins induce growth arrest is not known, however, in the case of $\mathrm{C} / \mathrm{EBP} \alpha$; arrest requires both the dimerization and DNA-binding domain of the protein (Umek et al. 1991). In characterizing the CHOPC/EBP DNA binding site we found that C/EBP homodimers can also bind the CHOP-C/EBP site (A. Crozat, H. Wu, J. Habener, and D. Ron, unpubl.). One possibility would therefore be, that arrest is effected by binding of either set of proteins, C/EBP dimers or CHOP-C/EBP heterodimers, to the same set of target genes. The apparent lower affinity of C/EBP dimers compared with CHOP-C/EBP heterodimers for the CHOP$\mathrm{C} / \mathrm{EBP}$ site suggests that smaller amounts of $\mathrm{CHOP}$ may be necessary to cause the same degree of growth inhibition. However, there is indirect evidence to suggest that in inducing growth arrest $\mathrm{CHOP}$ does more than merely serve as an agent for increasing the efficiency by which other C/EBP proteins are recruited to the putative arresting target genes; TLS-CHOP has dimerization characteristics that are indistinguishable from those of CHOP, possesses an intact basic region, and would therefore be expected to target C/EBP proteins as efficiently as CHOP, yet fails to induce growth arrest. This suggests that an effector function of $\mathrm{CHOP}$, presumably altered by the presence of TLS sequences in the chimeric protein, also plays an important role in inducing arrest.

TLS-CHOP fails to arrest cells. In addition, we have provided evidence that TLS-CHOP can block the inhibitory effect of $\mathrm{CHOP}$ on cell growth. There is no evidence for dimer formation between TLS-CHOP and CHOP; the bacterially expressed CHOP zipper probe fails to bind the abundant TLS-CHOP protein in the immunoprecipitation-zipper blot assay (Fig. 4C). In addition, we do not encounter coimmune precipitation of TLS-CHOP and CHOP (when precipitated with an antiTLS serum) even though under the same conditions, $\mathrm{C} / \mathrm{EBP} \beta$ is coprecipitated with TLS-CHOP /data not shown). Therefore, direct interference in $\mathrm{CHOP}$ function by TLS-CHOP seems unlikely. One possible mechanism by which TLS-CHOP may attenuate the growth-arresting properties of $\mathrm{CHOP}$ is by competing for limiting amounts of a C/EBP dimerization partner. We note that in the myxoid liposarcoma cell line 1955/91, saturating amounts of TLS, CHOP, and C/EBP $\beta$ antiserum precipitate roughly equal quantities of $\mathrm{C} / \mathrm{EBP} \beta$ protein (Fig. $4 \mathrm{Cl}$, implying that TLS-CHOP is present in quantities roughly equal to its major dimerization partner in these cells. This may have the effect of leaving little free C/EBP $\beta$ partner to interact with CHOP. However, the inability of TLS-CHOP to interfere with the growth-suppressing properties of $C / E B P \alpha$ and $C / E B P \beta$ suggests that TLS-CHOP interferes with CHOP activity by modulating an aspect of its function that may not be C/EBPdependent and there is more to TLS-CHOP action than merely inactivation of C/EBP partners.

We favor the hypothesis that the presence of TLS peptide sequence in the TLS-CHOP protein modifies the activity of an effector domain of CHOP resulting in a different regulatory signal from that elicited by the wildtype protein. It is this difference in a signaling function, presumably acting on putative $\mathrm{CHOP}$ target genes, that accounts for the ability of TLS-CHOP to attenuate CHOP-mediated arrest. Furthermore, the inability of TLS-CHOP to influence the activity of C/EBP $\alpha$ and C/EBP $\beta$ suggests that growth arrest by expression of $\mathrm{CHOP}$ is mediated by different target sites (and perhaps different target genes) than that caused by the C/EBP proteins.

The inhibitory effect of TLS-CHOP on CHOP-mediated growth arrest may play a role in cellular transfor- 
mation. We speculate that TLS-CHOP, by blocking the effect of CHOP, may inhibit an important pathway that controls cellular proliferation. Failure of this pathway leaves the cells exposed to the mutagenic effect of replicating their DNA under unfavorable growth conditions. It is intriguing that TLS-CHOP acts out its oncogenic role in the setting of the adipocyte. Perhaps this cell type is particularly dependent on the CHOP-C/EBPmediated checkpoint. The recent finding that nutrient deprivation can exert a marked stimulatory effect on the CHOP gene (Carlson et al. 1993) suggests one way by which TLS-CHOP oncogenic activity in the adipose cell may come about: Adipose tissue normally undergoes marked changes in nutritional status, periodically growing and involuting in response to changes in caloric intake. If periodic induction of CHOP is necessary to check the inappropriate proliferative potential of certain adipose cells in response to nutritional cues, it is easy to imagine how TLS-CHOP might interfere with this checkpoint and lead the cell on the path to transformation. The parallels in this model with the dominant transforming phenotype of certain p53 mutants is obvious (Finlay et al. 1989; Martinez et al. 1991). In both cases, the oncogenic form of the protein is presumed to exert its effect by interfering with an inducible $G_{1} / S$ checkpoint that is mediated by activation of the wildtype protein. p53 sits on a pathway that is used by a great many cells under diverse physiological conditionshence, the common finding of p53 mutations in human cancer-whereas CHOP is part of a more restricted pathway that may be particularly relevant to nutritional control of cellular proliferation in adipocytes.

\section{Materials and methods \\ Analysis of growth arrest by microiniection of expression plasmids}

Cells were grown on glass coverslips in $10 \%$ fetal calf serum (FCS). After reaching $\sim 50 \%$ confluence the cells were placed in $0.5 \%$ FCS to arrest them in $\mathrm{G}_{0}$. The cells were microinjected with plasmid DNA encoding the various CHOP derivatives 24 $48 \mathrm{hr}$ later. Microinjection was carried out using a Zeiss AIS system as described previously (Sorrentino et al. 1990). Following microinjection, the cells were placed in $20 \%$ FCS to stimulate progression through the cell cycle. Eighteen hours into the serum stimulation, BrdU was added to the culture medium to a final concentration of $100 \mu \mathrm{M}$ and the labeling procedure was carried out for an additional 6-8 hr. Supercoiled plasmid DNA diluted to a concentration of $100 \mathrm{ng} / \mathrm{ml}$ was used in the experiments in Figures 1,3 , and 4 . In experiments involving comicroinjection of two expression plasmids (Fig. 5) the concentration of the first effector $(\mathrm{CHOP}, \mathrm{C} / \mathrm{EBP} \alpha$, or $\mathrm{C} / \mathrm{EBP} \beta)$ was held at $50 \mathrm{ng} / \mathrm{ml}$ while TLS-CHOP was added to a final concentration of $100 \mathrm{ng} / \mathrm{ml}$.

Codetection of the CHOP and BrdU in the cells was performed essentially as described previously (Sorrentino et al. 1990). In brief, cells were fixed in paraformaldehyde and reacted with a primary rabbit antiserum directed against CHOP (Ron and Habener 1992). After washing away the primary antibody, rhodamine-conjugated anti-rabbit IgG was added to identify the $\mathrm{CHOP}$-expressing cells, and a fluorescein-conjugated anti-BrdU mouse monoclonal antibody (Boehringer Mannheim Biochemicals) was used to identify the cells in $\mathrm{S}$ phase of the cell cycle.
H-33258, a DNA stain, was used to identify all of the cells on the coverslips. The fluorescent signal was visualized using an epifluorescent microscope equipped with filters allowing discrimination between the rhodamine (CHOP), fluorescein (BrdU), and H33258 (all cells) signal.

Quantitative analysis of the degree of inhibition of progression to $\mathrm{S}$ phase was performed by evaluating all of the CHOPpositive cells on the injected coverslip to determine the fraction in $S$ phase and 400 noninjected cells from the same coverslip to determine the fraction of noninjected cells in S phase. Inhibition fraction was calculated by the formula $\%$ inhibition $=\mathbb{\|} \%$ uninjected (CHOP-negative) BrdU-positive cells] - [\% injected (CHOP-positive) BrdU-positive cells])/[\% uninjected (CHOPnegative) BrdU-positive cells] (Sorrentino et al. 1990).

A total of at least 60 positive cells (and, in most cases, $>100$ positive cells) were counted in each experiment. The results recorded are the mean and range of at least two identically performed experiments.

\section{Microinjection of CHOP protein}

Bacterially expressed GST fusion proteins of CHOP (GSTCHOP-WT) and a mutant form of CHOP, missing the leucine zipper dimerization domain (GST-CHOP- $\mathrm{LZ}^{-}$), were prepared and purified as described previously (Ron and Habener 1992), except that purification on the glutathione-Sepharose affinity matrix was carried out with two rounds of binding and elution after which the proteins were dialyzed against phosphate-buffered saline and concentrated by ultrafiltration (Amicon centriprep-10) to a final concentration of $10-15 \mathrm{mg} / \mathrm{ml}$. Cells growing on coverslips were arrested by growth in low senum and subsequently stimulated by adding media with $20 \%$ FCS. $\mathrm{CHOP}$ proteins were microinjected at a final concentration of $2-5 \mathrm{mg} / \mathrm{ml}$ at various time points following addition of serum, and the cells were processed for codetection of CHOP and BrdU as described above. We experimented with both nuclear and cytoplasmic injections of the proteins. The proteins were invariably found in the nucleus after as little as $30 \mathrm{~min}$ postinjection and no differences in growth inhibition were observed between the two injection modes.

\section{Plasmids and antisera}

Expression of $\mathrm{CHOP}$ and $\mathrm{CHOP}-\mathrm{LZ}^{-}$was directed by $\mathrm{CHOP}-$ (WT)pCDNA1 and CHOP(LZ-/pCDNAl as described previously (Ron and Habener 1992). CHOP protein was detected using a polyclonal rabbit serum raised against the full-length bacterially expressed CHOP-GST fusion protein (Ron and Habener 1992). The basic region mutant CHOP proteins (CHOPmutB and $\mathrm{CHOPmut} \mathrm{Cb} /$ contain internal deletions removing residues 101-122 and 109-122, respectively, from the CHOP basic region. To circumvent the deleterious effects of these deletions on the nuclear localization of the protein (A. Crozat, H. Wu, J. Habener, and D. Ron, unpubl.), a heterologous nuclear localization signal from the SV40 large $\mathrm{T}$ antigen was inserted in-frame at the amino terminus of the mutant $\mathrm{CHOP}$ molecule; this was accomplished by ligating an oligonucleotide encoding the sequence MPKKKRKVS into the CHOP cDNA at the position of the initiating methionine. This protein was expressed from the plasmid $\mathrm{CHOP}$ (mutBNLS)pCDNA1 and $\mathrm{CHOP}$ (mutCbNLS)pCDNA1. TLS-CHOP was expressed using the expression plasmid TLS-CHOPpCDNA1, and the protein was detected with the aforementioned anti-CHOP serum (Crozat et al. 1993). The C/EBP proteins were expressed using pCDNA1-based expression plasmids and were detected using a polyclonal antipeptide antiserum to the amino terminus of the protein in the case of $\mathrm{C} / \mathrm{EBP} \beta$ and an antisera raised against the full-length bacterially expressed GST fusion in the case of C/EBP $\alpha$ (Ron et al. 1992). 


\section{Detection of TLS-CHOP dimerization in vivo}

Immunoprecipitation and zipper blot experiments were carried out on the myxoid liposarcoma cell line 1955/91. This cell line contains an endogenous translocation-derived fusion gene encoding TLS-CHOP (Åman et al. 1992; Crozat et al. 1993). Nuclei were isolated and extracted in a high salt buffer containing Triton $1400 \mathrm{~mm} \mathrm{NaCl}, 20 \mathrm{~mm}$ HEPES at $\mathrm{pH} 7.9,1 \mathrm{~mm}$ EDTA, $0.1 \%$ Triton) as described (Schreiber et al. 1989). Extracts were immunoprecipitated with antisera directed against CHOP /see above), TLS [the amino terminus of the molecule (Crozat et al. 1993)], C/EBP $\alpha$, and C/EBP $\beta$ (see above). Immunoprecipitated proteins were boiled in $2 \%$ SDS and resolved by $11 \%$ SDSPAGE. Proteins in the gel were transferred to a nitrocellulose filter, and the filter was reacted with a ${ }^{32} \mathrm{P}$-labeled bacterially expressed dimerization probe consisting of the dimerization domain of C/EBP $\beta$ or CHOP (for details of the zipper blot procedure, see Ron and Dressler 1992).

\section{Acknowledments}

This work was supported by National Institutes of Health grants DK47119 and CA60945 to D.R. D.R. also acknowledges the support of the Pew Scholars Program in Biomedical Sciences. We thank Dr. Albert Fornace for useful discussions.

\section{References}

Åman, P., D. Ron, N. Mandahl, T. Fioretos, S. Heim, K. Arhenden, H. Willén, A. Rydholm, and F. Mitelman. 1992. Rearrangement of the transcription factor gene CHOP in myxoid liposarcomas with $\mathrm{t}(12 ; 160(\mathrm{q} 13 ; \mathrm{p} 11)$. Genes Chrom. Cancer 5: 271-277.

Carlson, S.G., T.W. Fawcett, J.D. Bartlett, M. Bernier, and N.J. Holbrook. 1993. Regulation of the C/EBP-related gene, gadd153, by glucose deprivation. Mol. Cell. Biol. 13: 4736-4744.

Chen, Q., K. Yu, N.J. Holbrook, and J.L. Stevens. 1992. Activation of the growth arrest and DNA damage-inducible gene gadd 153 by nephrotoxic cysteine conjugates and dithiothreitol. J. Biol. Chem. 267: 8207-8212.

Courtneidge, S.A., L. Goutebroze, A. Cartwright, A. Heber, S. Scherneck, and J. Feunteuen. 1991. Identification and characterization of the Hamster poloyomavinus middle $\mathrm{T}$ antigen. J. Virol. 65: 3301-3308.

Crozat, A.Y., P. Åman, N. Mandahl, and D. Ron. 1993. Fusion of CHOP to a novel RNA-binding protein in human myxoid liposarcoma with $\mathrm{t}(12 ; 16)(\mathrm{q} 13 ; \mathrm{p} 11)$. Nature 363: 640-644.

Descombes, P. and U. Schibler. 1991. A liver-enriched transcriptional activator protein, LAP, and a transcriptional inhibitory protein, LIP, are translated from the same mRNA. Cell 67: $569-579$.

Finlay, C.A., P.W. Hinds, and A.J. Levine. 1989. The p53 protooncogene can act as a suppressor of transformation. Cell 57: 1083-1093.

Fornace, A.J., D.W. Neibert, M.C. Hollander, J.D. Luethy, M. Papathanasiou, J. Fragoli, and N.J. Holbrook. 1989. Mammalian genes coordinately regulated by growth arrest signals and DNA-damaging agents. Mol. Cell. Biol. 9: 4196-4203.

Freytag, S.O. and T.J. Geddes. 1992. Reciprocal regulation of adipogenesis by Myc and C/EBP $\alpha$. Science 256: 379-382.

Hartwell, L. 1992. Defects in a cell cycle checkpoint may be responsible for the genomic instability of cancer cells. Cell 71: 543-546.

Hartwell, L.H. and T.A. Weinert. 1989. Checkpoints: Controls that ensure the order of cell cycle events. Science 246: 629634.
Kastan, M.B., O. Onyekwere, D. Sidransky, B. Vogelstein, and R.W. Craig. 1991. Participation of p53 in the cellular response to DNA damage. Cancer Res. 51: 6304-6311.

Kastan, M.B., O. Zhan, W.S. El-Deiry, F. Carrier, T. Jacks, W.V. Walsh, B.S. Plunkett, B. Vogelstein, and A. Fornace. 1992. A mammalian cell cycle checkpoint pathway utilizing p53 and GADD45 is defective in ataxia telangiectasia. Cell 71:587-597.

Kuerbitz, S.J., B.S. Plunkett, W.V. Walsh, and M.B. Kastan. 1992. Wild-type p53 is a cell cycle checkpoint determinant following irradiation. Proc. Natl. Acad. Sci. 89: 7491-7495.

Lin, D., M.T. Shields, S.J. Ullrich, E. Appela, and W.E. Mercer. 1992. Growth arrest induced by wild-type $\mathrm{p} 53$ protein blocks cells proir or near the restriction point late in G1 phase. Proc. Natl. Acad. Sci. 89: 9210-9214.

Lin, F.-T. and M.D. Lane. 1992. Antisense CCAAT/enhancerbinding protein RNA suppresses coordinate gene expression and triglyceride accumulation during differentiation of 3T3L1 preadipocytes. Genes \& Dev. 6: 533-544.

Livingston, L.R., A. White, J. Sprouse, E. Livanos, T. Jacks, and T.D. Tlsty. 1992. Altered cell cycle arrest and gene amplification potential accompany loss of wild-type p53. Cell 70: $923-935$.

Martinez, J., I. Georgoff, J. Martinez, and A.J. Levine. 1991. Cellular localization and cell cycle regulation by a temperaturesensitive p53 protein. Genes \& Dev. 5: 151-159.

McKinnon, P.J. 1987. Ataxia teleangiectasia: An inherited disorder of ionizing-radiation sensitivity in man. Hum. Genet. 75: 197-208.

Painter, R.B. and B.R. Young. 1980. Radiosensitivity in ataxia teleangiectasia: A new explanation. Proc. Natl. Acad. Sci. 77: 7315-7317.

Pardee, A.B. 1989. Gl events and regulation of cell proliferation. Science 246: 603-608.

Rabbitts, T.H., A. Forster, R. Larson, and P. Nathan. 1993. Fusion of the dominant negative transcription regulator $\mathrm{CHOP}$ with a novel gene FUS by translocation $t(12 ; 16)$ in malignant liposarcoma. Nature Genet. 4: 175-180.

Ron, D. and H. Dressler. 1992. pGSTag-A versatile bacterial expression plasmid for enzymatic labeling of recombinant proteins. BioTechniques 13: 866-869.

Ron, D. and J.F. Habener. 1992. CHOP, a novel developmentally regulated nuclear protein that dimerizes with transcription factors $\mathrm{C} / \mathrm{EBP}$ and LAP and functions as a dominant negative inhibitor of gene transcription. Genes \& Dev. 6: 439-453.

Schreiber, E., P. Matthias, M.M. Muller, and W. Schaffner. 1989. Rapid detection of octamer binding proteins with mini-extracts, prepared from small number of cells. Nucleic Acids Res. 17: 6419.

Sorrentino, V., R. Pepperkok, R.L. Davis, W. Ansorge, and L. Philipson. 1990. Cell proliferation inhibited by MyoD1 independently of myogenic differentiation. Nature 345: 813-815.

Umek, R.M., A.D. Friedman, and S.L. McKnight. 1991. CCAAT-enhancer binding protein: A component of a differentiation switch. Science 251: 288-292.

Weinert, T.A. and L.H. Hartwell. 1988. The RAD9 gene controls the cell cycle response to DNA damage in saccharomyces cerevisiae. Science 241: 317-322.

Yin, Y., M.A. Tainskey, F.Z. Bischoff, L.C. Strong, and G.M. Wahl. 1992. Wild-type p53 restores cell cycle control and inhibits gene amplification in cells with mutant p53 alleles. Cell 70: 937-948.

Zhan, Q., D.A. Lieberman, I. Alamo, M.C. Hollander, D. Ron, K.W. Khon, B. Hoffman. 1994. The gadd and MyoD genes define a novel set of mammalian genes encoding acidic proteins that cooperatively supress cell growth. Mol. Cell. Biol. 12: (in press). 


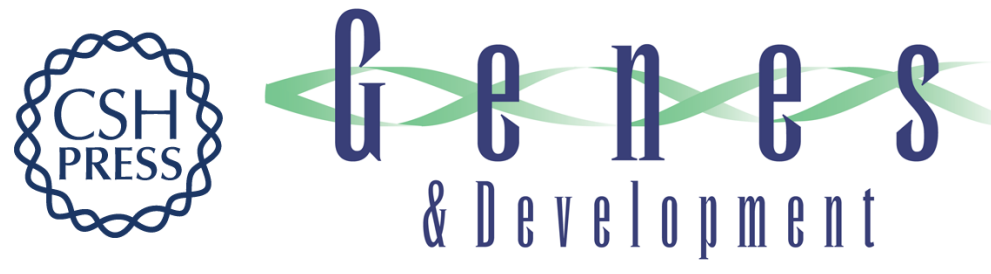

\section{CHOP (GADD153) and its oncogenic variant, TLS-CHOP, have opposing effects on the induction of $\mathrm{G} 1 / \mathrm{S}$ arrest.}

M V Barone, A Crozat, A Tabaee, et al.

Genes Dev. 1994, 8:

Access the most recent version at doi:10.1101/gad.8.4.453

References This article cites 29 articles, 16 of which can be accessed free at:

http://genesdev.cshlp.org/content/8/4/453.full.html\#ref-list-1

License

Email Alerting

Service

Receive free email alerts when new articles cite this article - sign up in the box at the top right corner of the article or click here.

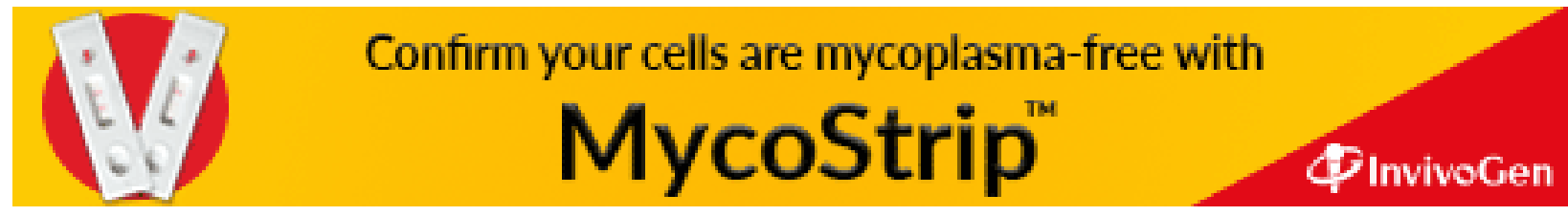

